\title{
Dental Calculus
}

National Cancer Institute

\section{Source}

National Cancer Institute. Dental Calculus. NCI Thesaurus. Code C60715.

Mineralized deposit that forms on the teeth or dental prostheses. 